This is an author produced version of a paper published in Remote Sensing Letters.

This paper has been peer-reviewed but may not include the final publisher proof-corrections or pagination.

Citation for the published paper:

Persson, H.J. \& Perko, R. (2016) Assessment of boreal forest height from

WorldView-2 satellite stereo images. Remote Sensing Letters. Volume: 7,

Number: 12, pp 1150-1159.

http://dx.doi.org/10.1080/2150704X.2016.1219424.

Access to the published version may require journal subscription.

Published with permission from: Taylor \& Francis.

Standard set statement from the publisher:

This is an Accepted Manuscript of an article published in Remote Sensing Letters on 19 aug 2016, available online:

http://www.tandfonline.com/10.1080/2150704X.2016.1219424

Epsilon Open Archive http://epsilon.slu.se 


\section{Assessment of boreal forest height from WorldView-2 satellite stereo images}

\section{HENRIK PERSSON ${ }^{1 *}$, ROLAND PERKO $^{2}$}

${ }^{I}$ Department of Forest Resource Management, Swedish University of Agricultural Sciences, Umeå, Sweden

${ }^{2}$ Institute for Information and Communication Technologies, DIGITAL, JOANNEUM RESEARCH Forschungsgesellschaft mbH, Graz, Austria

Corresponding author:

Henrik Persson

Swedish University of Agricultural Sciences

Remote Sensing

SE-901 83 UMEA

Phone: +46907868105

henrik.persson@slu.se 


\section{Assessment of boreal forest height from WorldView-2 satellite stereo images}

WorldView-2 satellite stereo images were used to derive a digital surface model, which together with a high resolution digital terrain model from airborne laser scanning (ALS) were used to estimate forest height. Lorey's mean height $\left(\mathrm{H}_{\mathrm{L}}\right)$ could be estimated with a root mean square error (RMSE) of $1.5 \mathrm{~m} \mathrm{(8.3 \% )} \mathrm{and}$ $1.4 \mathrm{~m}$ (10.4\%), using linear regression, at the two Swedish test sites

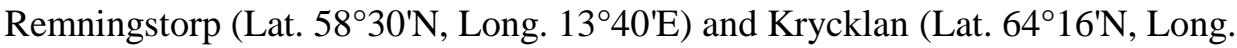
$\left.19^{\circ} 46^{\prime} \mathrm{E}\right)$, which contain hemi-boreal and boreal forest. The correlation coefficients were $r=0.94$ and $r=0.91$, respectively. The $10 \mathrm{~m}$ sample plots were 175 in Remningstorp and 282 in Krycklan. It was furthermore found, that WorldView-2 data are sometimes unstable for canopy top height estimations (ALS height percentile 100, p100) and that the reconstructed heights are generally located below the actual top height. The WorldView-2 p60 was found to correlate best with ALS p70 in Remningstorp, while WorldView-2 p95 was found to correlate best with ALS p70 in Krycklan, and it moreover reached the highest correlation for all other estimated variables, at both test sites. It was concluded, that WorldView-2 p95 height data overall represents approximately the forest height ALS p70. The overall high correlation coefficients above 0.90 at both test sites, with different forest conditions, indicate that stereo matching of WorldView-2 satellite images is suitable for forest height mapping.

Keywords: forestry, canopy height, photogrammetry, satellite observations 


\section{Introduction}

Detailed and accurate updated information about the forest is vital for planning forest management actions, and also for following the current forest biomass inventory. The necessary information has traditionally been collected from sample based field visits (Nilsson 2013). Remote sensing techniques can provide comprehensive and accurate information in order to further increase the value of the field inventoried data (Tomppo et al. 2008). Remote sensing data have in numerous studies been shown to complement field based measures and estimations, such as basal area-weighted tree height (also known as Lorey's mean height, $\mathrm{H}_{\mathrm{L}}$ ), basal-area weighted stem diameter and mean stem volume (Hyyppä et al. 2000; Næsset et al. 2004; Yu et al. 2015). $H_{L}$ weights the contribution of trees to the stand height by their basal area, which causes larger trees to have a greater impact on the mean height. This measure is widely used in the forestry in US and Europe, and gives a more robust mean height in uneven stands compared to the arithmetic mean height which can be meaningful especially in even-aged stands.

Currently, airborne laser scanning (ALS) is the most accurate airborne remote sensing technique available for estimation of many forest variables, such as $\mathrm{H}_{\mathrm{L}}$, basal area or stem volume (Hyyppä et al. 2000; Næsset et al. 2004; Yu et al. 2015). However, satellite based platforms can provide information over large areas at lower cost and with short repetition intervals. Satellite images consisting of optical acquisitions with the spectral bands correlating with different forest variables in a 2-dimensional (2D) manner have been used for many decades. However, one important factor that makes ALS superior to other techniques have been its ability of reconstructing the forest in 3 dimensions (3D). A balance of using the satellite platform and still obtain 3D data can be achieved by deriving a digital surface model (DSM) via stereo matching of optical 
satellite images and then a canopy height model can be computed, if an accurate digital terrain model (DTM) is available.

Technical sensor improvements in the last decade have made sensors available which offer a ground sampling distance (GSD) below one meter and this set of sensors are frequently denoted very high resolution (VHR) sensors. Steerable sensors make stereo or even tri-stereo acquisitions available from a single overpass, which is crucial to obtain two cloud free images within a short temporal baseline. There are thus far only a limited number of studies which have used VHR sensors for estimation of forest variables. St-Onge et al. (2008) evaluated the accuracy of forest height and aboveground biomass (AGB) based on an Ikonos stereo pair and an ALS DTM at a Canadian test site located close to Quebec. Straub et al. (2013) used Cartosat-1 and WorldView-2 (WV2) stereo images to estimate growing stock in a mixed German forest. Immitzer et al. (2016) used WV2 stereo images in combination with national forest inventory data to map growing stock wall-to-wall in Bavaria, Germany.

So far, Yu et al. (2015) is the only study known to the authors, that has used WV2 data to evaluate forest variables in boreal forest (Finland). They compared numerous remote sensing techniques to estimate $\mathrm{AGB}$, stem volume, basal-area, basal area-weighted mean diameter and $\mathrm{H}_{\mathrm{L}}$ at plot-level. One technique was stereo matched WV2 images, where the RMSE was found to be $1.4 \mathrm{~m}$ for estimation of $\mathrm{H}_{\mathrm{L}}$. The limited experience from stereo matched VHR WV2 images in boreal forest is the highest motivation for this study.

The main objectives of this study are to examine the estimation of forest height at plot-level by using stereo matched very high resolution WorldView-2 satellite images, and an airborne laser scanning based digital terrain model. This is achieved by estimating field sampled $\mathrm{H}_{\mathrm{L}}$ and moreover by comparisons with ALS height percentiles. 


\section{Study area and materials}

\subsection{Test sites}

Two Swedish test sites located in the boreal forest zone were used (Figure 1). [Figure1]. The first test site was Remningstorp located in southern Sweden (Lat. 58³0'N, Long. $13^{\circ} 40^{\prime} \mathrm{E}$ ), and comprises about 1,200 ha of productive forest land. The prevailing tree species were Norway spruce (Picea abies; 68\% volume), Scots pine (Pinus sylvestris; $18 \%$ volume) and birch (Betula pendula and Betula pubescens; $13 \%$ volume). It is a rather flat region with moderately varying ground elevations between $120 \mathrm{~m}$ and $145 \mathrm{~m}$ above sea level and slopes up to $21^{\circ}$.

The second test site is the Krycklan river catchment area located in northern Sweden (Lat. $64^{\circ} 16^{\prime} \mathrm{N}$, Long. $\left.19^{\circ} 46^{\prime} \mathrm{E}\right)$. The prevailing tree species were Scots pine (44\% volume, mainly in dry upslope areas), Norway spruce (38.6\% volume, mainly in wetter, low-lying areas), and birch (17.1\% volume). The region is hilly with elevations between $125 \mathrm{~m}$ and $350 \mathrm{~m}$ above sea level and slopes up to $61^{\circ}$.

\subsection{Field data}

A systematic grid of circular plots with $10 \mathrm{~m}$ radius was distributed at both test sites. In Remningstorp 219 plots with about $200 \mathrm{~m}$ spacing were inventoried in the fall 2014. In Krycklan 326 plots with about $350 \mathrm{~m}$ spacing were inventoried in the fall 2015 . The distribution of plots within the test sites is shown in Figure 1. The plot locations were measured using a Trimble GeoExplorer 6000 GeoXR, and all trees with a diameter at breast height $(\mathrm{DBH}) \geq 0.04 \mathrm{~m}$ were calipered. The height was measured on a subsample of the trees, using a hypsometer. The tree height distribution at the two test sites is presented in Figure 2 and some statistical measures are presented in Tables 1 and 2. [Figure 2] [Table 1] [Table 2]. 


\subsection{Remote sensing data}

ALS height data were collected for the test sites approximately the same time as the field and satellite data. Remningstorp was scanned 4 August 2014 with a Riegl LMS 680i laser scanner at $240 \mathrm{kHz}$ PRF and with more than 20 points $/ \mathrm{m}^{2}$ density. The wavelength was $1550 \mathrm{~nm}$. Krycklan was scanned 22 and 23 August 2015 with a Titan L359 laser scanner at $300 \mathrm{kHz}$ PRF and with more than 20 points $/ \mathrm{m}^{2}$ density. The wavelength was $1064 \mathrm{~nm}$.

The DTM utilized was produced by the Swedish National Land Survey (Lantmäteriet) from ALS data, with 0.5 points $/ \mathrm{m}^{2}$ point density, and $2 \mathrm{~m}$ pixel size (Rönnberg 2011; Bergström, Melin, and Nicolausson 2009).

Optical satellite images were acquired from the WV2 satellite in 2015. The images were acquired as panchromatic along-track stereo pairs, with a spatial resolution of $0.5 \mathrm{~m}$. The details about the satellite images are shown in Table 3.

\section{Methods}

\subsection{Refinement of field data}

Linear regression was used to assign local height values species-wise to all inventoried trees at respective test site. The models had the form of (Söderberg 1986):

$$
\ln H=D+\ln D
$$

where $H$ is the field measured height and $D$ means DBH. The cross-validated accuracy was $3.3 \mathrm{~m}(15.6 \%)$ RMSE for pine, $2.2 \mathrm{~m}(11.5 \%)$ for spruce, and $2.9 \mathrm{~m}(18.7 \%)$ for deciduous (birch) at Remningstorp, and correspondingly $2.4 \mathrm{~m}(16.4 \%)$ for pine, $1.9 \mathrm{~m}$ (13.8\%) for spruce, and $2.0 \mathrm{~m}(15.1 \%)$ for deciduous (birch) at Krycklan. The forestry variable $\mathrm{H}_{\mathrm{L}}$ was computed plot-wise, according to 


$$
H_{L}=\frac{\sum B H}{\sum B}
$$

where $B$ is the basal area.

Plot-wise averages were extracted and those with a mean height corresponding to an ALS p100 of less than $4 \mathrm{~m}$ (equivalent to $\mathrm{DBH}=0.04 \mathrm{~m}$ ) were removed and furthermore plots that have been clear-cut since the field inventory (1 year difference in Remningstorp), or were located within approximately $10 \mathrm{~m}$, were removed.

\subsection{ALS height data processing}

The point clouds acquired from ALS were post-processed with the software Lastools. The ground was classified and then the point elevations above the ground were computed. The point cloud was filtered for noise, and points above $40 \mathrm{~m}$ were dropped, to avoid errors from for example birds. Metrics were extracted plot-wise above a $1.37 \mathrm{~m}$ height-cut-off to avoid under vegetation. The metrics included the height percentiles p50, p60, p70, p80, p90, p95, p99, p100, average, and standard deviation.

The matched WV2 heights were compared with all ALS height percentiles. The ALS height percentile 100 corresponds to the maximum tree height and is close to the dominant height in a forest. Moreover, the highest correspondence between ALS heights and WV2 heights was examined among all extracted ALS height percentiles, and the highest correspondence was found for the ALS p70, which was also expected to be close to $\mathrm{H}_{\mathrm{L}}$. Hence results for these height percentiles are presented in addition to $\mathrm{H}_{\mathrm{L}}$.

\subsection{DSM generation via stereo matching of satellite image pairs}

The geo-location accuracy inherent to WV2 panchromatic imagery is reported to be $5 \mathrm{~m}$ CE90 at less than $30^{\circ}$ off-nadir direction according to the satellite owner DigitalGlobe. However, the geo-location accuracy was improved by positioning $\sim 10$ ground control 
points (GCPs) per image manually. The resulting root mean square error (RMSE) of the triangulation solution was $<1$ pixel.

The stereo matching (and belonging geo-location optimization) was computed with the software Remote Sensing Graz (RSG). It used epipolar rectification of the images based on optimized sensor models, derived from the GCPs. Hence, a pre-defined point in the reference image can be found along a horizontal line in the search image. A semi-global image matching, similar to (Hirschmüller 2008), was used to compute disparities for each pixel for the stereo pair. Finally, spatial point intersection was applied to calculate ground coordinates in a least-squares manner out of the image matching disparities. The employed procedure is very similar to the more comprehensive description in Perko et al. (2014). The final step resulted in a 3D point cloud, from which the same plot-wise metrics as for ALS data were extracted.

\subsection{Modelling and evaluation}

Plot-wise metrics of the stereo matched WV2 point clouds were used in linear regression models to model the ALS percentiles, extracted the same way, from its point clouds. All extracted metrics were individually cross-compared, leading to the models presented in Table 4, which were found to perform the best.

To evaluate the explanation performance of respective variable with WV2 data, the RMSE and the relative RMSE were computed (Hyndman and Koehler 2006):

$$
\begin{gathered}
\operatorname{RMSE}=\sqrt{\frac{\sum_{i=1}^{n}\left(\hat{X}_{i}-X_{i}\right)^{2}}{n}} \\
\operatorname{RMSE}(\%)=\frac{\operatorname{RMSE}}{\bar{X}}
\end{gathered}
$$


where $n$ is the number of plots, $\hat{X}_{i}$ the value estimated from WW2 data for plot $i$, and $X_{i}$ the observed value for plot $i . \bar{X}$ represents the sampled mean for the variable in question. Moreover, the correlation coefficient $r$ and the adjusted coefficient of determination $\left(R_{\text {adj }}^{2}\right)$ were also computed (Kvålseth 1985).

\section{Results and discussion}

Linear regression models with one of the WV2 height percentiles as explanatory variable were applied successfully in order to describe the variable in question. $\mathrm{H}_{\mathrm{L}}$ could be estimated from WV2 data with $1.5 \mathrm{~m}$ and $1.4 \mathrm{~m}$ RMSE at respective test site, which corresponds to $8.3 \%$ and 10.0\% RMSE (Table 4, Figures 3(a) and 3(d)). [Figure 3] [Table 4]. This corresponds well with the 1.4 m RMSE reported by Yu et al. (2015) for a Finnish test site. The top height, ALS p100, was estimated with slightly larger RMSE at both test sites (2.1 m and $1.7 \mathrm{~m}$ respectively; Figures 3(c) and 3(f)). The highest correlation and lowest RMSE for all possible combinations was found for ALS p70 at both test sites, which in Remningstorp was best described with WV2 p60, while in Krycklan WV2 p95 was the best estimator (Table 4, Figures 3(b) and 3(e)). The RMSEs were $0.8 \mathrm{~m}(5.8 \%)$ and $1.1 \mathrm{~m}(9.5 \%)$ at the respective test sites, which are lower than traditional field sampled methods (subjectively chosen locations evaluated using a relascope, about $10 \%$ to $15 \%$ RMSE) and in line with the accuracy with which $\mathrm{H}_{\mathrm{L}}$ can be estimated from ALS data (Ståhl 1992; Yu et al. 2015).

The trees sampled in field contain inherent errors of the DBH and tree height. The DBH is normally accurately measured with errors below a few centimetres, while the height can differ more, and especially since linear regression was used to assign height values to all trees without measured heights. Therefore the high similarity with ALS p70, which likely could be close to $\mathrm{H}_{\mathrm{L}}$, gives an extra indication that the applied method is plausible for estimation of forest height. 
The WV2 p95 was the strongest explanatory variable for all the other estimated variables at both test sites. This is likely due to that WV2 p100 was overall less robust (compared to WV2 p95), and lower WV2 height percentiles were generally originating from reflections too deep into the canopy. As the stereo matched WV2 point cloud originates from optical images with spectral wavelengths $(450-800 \mathrm{~nm})$, no or a limited depth sensibility was expected. This hence causes most of the height percentiles from the WV2 point cloud to be rather tightly gathered, and it was expected, that the WV2 point cloud would correspond approximately to the canopy top height (ALS p100). However, as the highest correlation and lowest RMSE was found for the ALS p70, it can be concluded, that robust upper height percentiles (WV2 p95) from the VHR optical stereo matched images rather describe a forest height of about $70 \%$ of the top height.

The canopy height is not a "fix" height, but rather an average of several tree heights, dependant on the spatial scale that is sampled. When the forest top height (ALS p100) was studied, a number of plots started to "stand out", by becoming more prominently underestimated (Figures 3(c) and 3(f)). From investigations of these plots, many of them seem to be located in forest with low trees and frequently also rather sparse forest. Some of the underestimated plots contained two-layered forest, often originating from left seeding trees in younger stands, which in a sense can be considered sparse forest.

All forest height related variables were estimated with high correlations ( $r$ at least 0.90$)$ at both test sites with in-situ modelling data. The image resolution plays likely a vital role for this success, as stereo matching of lower resolution images have indicated little contribution for this type of applications (Persson et al. 2012). Moreover, the high geo-location accuracy causes the large intersection angles to come to their full potential, as a good matching can be achieved despite the somewhat different object 
appearances within the stereo pair. With lower resolution and worse geo-location accuracy, the challenge of matching the same objects in different images increase.

As few/no plots with very young forest were included (trees $<10-30$ years depending on the test site), caution should be taken before extrapolating these models to entire wall-to-wall maps including all kinds of forest. Furthermore, as the variable to be estimated shifted upwards in the forest canopy, the younger plots became more underestimated. Future studies should further investigate the influence of forest density, i.e., by also considering forest variables such as basal-area and stem volume.

\section{Conclusions}

This article shows how WV2 satellite images can be stereo matched in order to derive the forest height. The presented method requires a high resolution DTM, which in our case was obtained from ALS, in order to compute the difference between stereo matched heights and the ground. These height differences were extracted plot-wise on $10 \mathrm{~m}$ sample plots in order to obtain the forest height. Three variables were evaluated to express the forest height; $\mathrm{H}_{\mathrm{L}}$ (basal area-weighted mean tree height), ALS p100 (canopy top height, close to the dominant forest height and corresponds to the maximum tree height), and moreover the most correlated ALS height percentile, which turned out to be ALS p70. The proposed approach was evaluated on a few hundreds of $10 \mathrm{~m}$ plots at two Swedish test sites with hemi-boreal and boreal forest respectively, which mainly contained coniferous forest.

The results show that stereo matched WorldView-2 images seem suitable to efficiently map forest height. It is potentially also well suited for updating existing inventories, which often are based on more expensive ALS. The presented approach can likely be used similarly in large parts of the boreal forests, as similar results were obtained across the test sites, and moreover, the results obtained in this study confirm 
other studies from for example, German and Canadian forests, which contain a higher degree of deciduous forest (St-Onge, Hu, and Vega 2008; Maack et al. 2015). The plotlevel results of about $6 \%$ to $10 \%$ RMSE are better than traditional field inventory methods currently used by many Swedish forest companies. A general tendency to underestimation of higher trees could be noticed, and this tended to be most prominent for the estimations of $\mathrm{H}_{\mathrm{L}}$ and ALS p100.

\section{Acknowledgment}

The authors would like to acknowledge Dr. Johan Fransson, Prof. Håkan Olsson, Prof. Mathias Schardt, Dr. Karlheinz Gutjahr, and Dr. Johann Raggam for valuable discussions.

\section{Disclosure statement}

The authors declare no conflicts of interest.

\section{References}

Bergström, Helena, Hanna Melin, and Anders Nicolausson. 2009. Höjddata - En Förutsättning För Klimatanpassning. Gävle, Sweden: Swedish National Land Survey.

Hirschmüller, H. 2008. "Stereo Processing by Semiglobal Matching and Mutual Information.” Pattern Analysis and Machine Intelligence, IEEE Transactions on 30 (2): 328-341. doi:10.1109/TPAMI.2007.1166.

Hyndman, Rob J, and Anne B Koehler. 2006. "Another Look at Measures of Forecast Accuracy." International Journal of Forecasting 22: 679-688. doi:10.1016/j.ijforecast.2006.03.001. 
Hyyppä, Juha, Hannu Hyyppä, Mikko Inkinen, Marcus Engdahl, Susan Linko, and YiHong Zhu. 2000. “Accuracy Comparison of Various Remote Sensing Data Sources in the Retrieval of Forest Stand Attributes." Forest Ecology and Management 128 (1-2): 109-120. doi:10.1016/S0378-1127(99)00278-9.

Immitzer, Markus, Christoph Stepper, Sebastian Böck, Christoph Straub, and Clement Atzberger. 2016. "Forest Ecology and Management Use of WorldView-2 Stereo Imagery and National Forest Inventory Data for Wall-to-Wall Mapping of Growing Stock." Forest Ecology and Management 359. Elsevier B.V.: 232-246. doi:10.1016/j.foreco.2015.10.018.

Kvålseth, TO. 1985. “Cautionary Note about R 2.” The American Statistician 39 (4): $279-285$.

Maack, Joachim, Teja Kattenborn, Fabian Ewald Fassnacht, Fabian Enßle, Jaime Hernández, Patricio Corvalán, and Barbara Koch. 2015. "Modeling Forest Biomass Using Very-High-Resolution Data - Combining Textural, Spectral and Photogrammetric Predictors Derived from Spaceborne Stereo Images.” European Journal of Remote Sensing 48: 245-261. doi:10.5721/EuJRS20154814.

Næsset, Erik, Terje Gobakken, Johan Holmgren, Hannu Hyyppä, Juha Hyyppä, Matti Maltamo, Mats Nilsson, Håkan Olsson, Åsa Persson, and Ulf Söderman. 2004. "Laser Scanning of Forest Resources: The Nordic Experience.” Scandinavian Journal of Forest Research 19 (6): 482-499. doi:10.1080/02827580410019553.

Nilsson, Malin. 2013. "Knowledge in the Forest Planning Process." Swedish University of Agricultural Sciences. http://pub.epsilon.slu.se/10253/1/nilsson_m_130423.pdf.

Perko, Roland, Hannes Raggam, Karlheinz Gutjahr, and Mathias Schardt. 2014. 
“Assessment of the Mapping Potential of Pléiades Stero and Triplet Data.” In ISPRS Annals of the Photogrammetry, Remote Sensing and Spatial Information Sciences, II-3:103-109. doi:10.5194/isprsannals-II-3-103-2014.

Persson, Henrik, Jörgen Wallerman, Håkan Olsson, and Johan E.S. Fransson. 2012. "Estimating Biomass and Height Using DSM from Satellite Data and DEM from High-Resolution Laser Scanning Data.” In IGARSS 2012, 1649-1651. 22-27 July, Munich, Germany.

Rönnberg, Andreas. 2011. Kartografisk Information Ur Laserdata. Vol. 1. Gävle, Sweden.

St-Onge, B., Y. Hu, and C. Vega. 2008. "Mapping the Height and above-Ground Biomass of a Mixed Forest Using Lidar and Stereo Ikonos Images.” International Journal of Remote Sensing 29 (5): 1277-1294. doi:10.1080/01431160701736505.

Straub, Christoph, Jiaojiao Tian, Rudolf Seitz, and Peter Reinartz. 2013. “Assessment of Cartosat-1 and WorldView-2 Stereo Imagery in Combination with a LiDAR-DTM for Timber Volume Estimation in a Highly Structured Forest in Germany." Forestry 86 (July): 463-473. doi:10.1093/forestry/cpt017.

Ståhl, Göran. 1992. A Study on the Quality of Compartmentwise Forest Data Acquired by Subjective Inventory Methods. Vol 24. Umeå, Sweden.

Söderberg, Ulf. 1986. Funktioner För Skogliga Produktionsprognoser: Tillväxt Och Formhöjd För Enskilda Träd Av Inhemska Trädslag I Sverige. Rapport (Sveriges Lantbruksuniversitet. Avdelningen for Skogsuppskattning Och Skogsindelning). Umeå, Sweden: Sveriges lantbruksuniversitet. 
Tomppo, Erkki, Håkan Olsson, Göran Ståhl, Mats Nilsson, Olle Hagner, and Matti Katila. 2008. “Combining National Forest Inventory Field Plots and Remote Sensing Data for Forest Databases.” Remote Sensing of Environment 112 (5): 1982-1999. doi:10.1016/j.rse.2007.03.032.

Yu, Xiaowei, Juha Hyyppä, Mika Karjalainen, Kimmo Nurminen, Kirsi Karila, Antero Kukko, Anttoni Jaakkola, et al. 2015. “Comparison of Laser and Stereo Optical, SAR and InSAR Point Clouds from Air- and Space-Borne Sources in the Retrieval of Forest Inventory Attributes.” Remote Sensing 7 (12): 15933-15954. doi:10.3390/rs71215809. 


\section{Tables}

Table 1. Field plot properties for $\mathrm{H}_{\mathrm{L}}$. The "number of plots used" contains no clear-cut plots or plots with mean ALS p100<4 m.

\begin{tabular}{lllllll}
\hline Test site & Number of & Number of & Mean & Min & Max & Standard \\
& inventoried & plots used & $(\mathbf{m})$ & $(\mathbf{m})$ & $(\mathbf{m})$ & deviation \\
& plots & & & & & $(\mathbf{m})$ \\
\hline Remningstorp & 219 & 175 & 18.7 & 6.04 & 28.0 & 4.66 \\
Krycklan & 326 & 282 & 14.4 & 4.42 & 24.6 & 3.57
\end{tabular}

Table 2. Number of inventoried trees at respective test site, presented species-wise. The DBH was always measured for all trees where the height was measured.

\begin{tabular}{llll}
\hline Test site & Species & No. of trees & No. of trees \\
& & $(\mathbf{D B H})$ & (height) \\
\hline Remningstorp & Spruce & 3930 & 1071 \\
Remningstorp & Deciduous & 1860 & 506 \\
Remningstorp & Pine & 465 & 239 \\
Krycklan & Spruce & 5869 & 1064 \\
Krycklan & Deciduous & 3439 & 506 \\
Krycklan & Pine & 6256 & 1942
\end{tabular}

Table 3. Details for the WV2 satellite images.

\begin{tabular}{lllll}
\hline Test site & Date of & In-track & Across-track & Intersection \\
& acquisition & view angle $\left(^{\circ}\right)$ & view angle $\left(^{\circ}\right)$ & angle $\left(^{\circ}\right)$ \\
\hline Remningstorp 1 & 11 Sep 2015 & -14.6 & -20.8 & \} 27.1 \\
Remningstorp 2 & 11 Sep 2015 & 12.5 & -20.0 & \\
Krycklan \#1 & 11 Sep 2015 & -23.0 & -22.3 & \} 29.7 \\
Krycklan \#2 & 11 Sep 2015 & 6.7 & -21.7 &
\end{tabular}


Table 4. Results of estimations at $10 \mathrm{~m}$ radius plot-level. ALS p70 and ALS p100 are the airborne laser scanning percentiles 70 and 100.

\begin{tabular}{lllllll}
\hline Test site & Estimated & Explanatory & RMSE & RMSE & $\boldsymbol{r}$ & $R_{\text {adj }}^{2}$ \\
& variable & variable & $(\mathbf{m})$ & $(\%)$ & & \\
\hline Remningstorp & $\mathrm{H}_{\mathrm{L}}$ & WV2 p95 & 1.5 & 8.3 & 0.94 & 0.89 \\
Remningstorp & ALS p70 & WV2 p60 & 0.8 & 5.8 & 0.96 & 0.96 \\
Remningstorp & ALS p100 & WV2 p95 & 2.1 & 9.4 & 0.90 & 0.81 \\
Krycklan & HL & WV2 p95 & 1.4 & 10.0 & 0.91 & 0.83 \\
Krycklan & ALS p70 & WV2 p95 & 1.1 & 9.5 & 0.95 & 0.90 \\
Krycklan & ALS p100 & WV2 p95 & 1.7 & 9.4 & 0.92 & 0.85
\end{tabular}

\section{Figure captions}

Figure 1. The two test sites Remningstorp (right) and Krycklan (left), located in southern $\left(58^{\circ} \mathrm{N}\right)$ and northern $\left(64^{\circ} \mathrm{N}\right)$ Sweden (middle), respectively. The absence of plots in the systematic grids are plots located on non-forest land (e.g., lakes, roads or meadows).

Figure 2. Height distribution of $\mathrm{H}_{\mathrm{L}}$ for the $10 \mathrm{~m}$ field plots at respective test site. a) Remningstorp b) Krycklan.

Figure 3. Estimation of heights at the test sites at plot-level with 10 m radius.

(a) $\mathrm{H}_{\mathrm{L}}$ in Remningstorp.

(b) ALS p70 in Remningstorp.

(c) ALS p100 (top height) in Remningstorp.

(d) $\mathrm{H}_{\mathrm{L}}$ in Krycklan.

(e) ALS p70 in Krycklan.

(f) ALS p100 (top height) in Krycklan. 